\title{
Liver Abscesses: What Diagnostics and Therapeutics in the Kati Reference Health Center (Mali)?
}

\author{
Abdoulaye Diarra ${ }^{1 *}$, Koniba Keita ${ }^{1}$, Amadou Traore1, Assitan Koné1, Madiassa Konate1, \\ Idrissa Tounkara', Mamadou A. Keita1, Issa Traore', Modibo Togola ${ }^{2}$, Fadima K. Tall2, \\ Daouda Diallo², Moustaph Issa Magane ${ }^{2}$, Deborah Sanra Sanogo ${ }^{3}$, Aboubacar Koné1, \\ Ibrahim Diakite ${ }^{1}$, Alhassane Traore ${ }^{1}$, Adégné Togo ${ }^{1}$
}

\author{
${ }^{1}$ General Surgery Department, Kati, Mali \\ ${ }^{2}$ Anesthesia Service and Resuscitation Department, Kati, Mali \\ ${ }^{3}$ Gastroenterology Department, Kati, Mali \\ Email: *abdoulayeg2004@yahoo.fr
}

How to cite this paper: Diarra, A., Keita, K., Traore, A., Koné, A., Konate, M., Tounkara, I., Keita, M.A., Traore, I., Togola, M., Tall, F.K., Diallo, D., Magane, M.I., Sanogo, D.S., Koné, A., Diakite, I., Traore, A. and Togo, A. (2018) Liver Abscesses: What Diagnostics and Therapeutics in the Kati Reference Health Center (Mali)? Surgical Science, 9, 344-350.

https://doi.org/10.4236/ss.2018.99041

Received: September 4, 2018

Accepted: September 25, 2018

Published: September 28, 2018

Copyright (๑) 2018 by authors and Scientific Research Publishing Inc. This work is licensed under the Creative Commons Attribution International License (CC BY 4.0).

http://creativecommons.org/licenses/by/4.0/ (c) (i) Open Access

\begin{abstract}
The objectives were to determine the frequency of hepatic abscess, and to describe the clinical and para-clinical aspects and the therapeutic modalities. Method and material: This is a prospective study covering 24 months (January 2016-December 2017). Results: This was a prospective study of 30 cases of liver abscess, ranging from January 2016 to December 2017, a period of 12 months. Inclusion criteria: What were included in this study were all patients hospitalized and treated for liver abscess. Criteria for non-inclusion: Abscess cases have not been treated in the service. The sex ratio was 2.3 and the average age was 35 years old. The main clinical signs were: fever (56.7\%), hepatitis (73.3\%) and hepatomegaly (26.7\%). Hepatic collections objected to abdominal ultrasonography were localized in the right lobe in $70 \%$. Surgical treatment was performed in $10 \%$ of cases. Medical treatment alone was performed in the majority of cases (56.7\%); eclocated puncture was required in 10 cases $(33.3 \%)$. The follow-up was simple in all our patients and we did not register deaths; the average duration of treatment was 5 days. Conclusion: Topical pathology in surgical practice in our country, liver abscess is common in our department; medical treatment is curative in the absence of complications.
\end{abstract}

\section{Keywords}

Abscess, Liver, Mali 


\section{Introduction}

The abscess corresponds to a neoformed cavity created by the necrosis of the hepatic parenchyma induced by the pathogenic agent [1]. Liver abscesses can be divided according to the infectious agent involved (bacteria, parasites, fungi) [2]. In Southeast Asia: Amebiasis disease occurs in $15 \%$ of healthy carriers and is responsible for $25 \%$ of liver abscess [2] [3] [4]. It is an import pathology because of immigration and tourism [5] [6] [7]. According to the WHO, 10\% of the population is infected, which corresponds to about 500 million people [3] [4] [5]. In Mali in 2012, 50 cases of liver abscess were diagnosed and treated in the General Surgery Department at CHU Gabriel [8]. The incidence of non-parasitic abscesses has doubled in the last two decades because of HIV/AIDS. The diagnosis is clinical in front of the Fontan triad, confirmed by ultrasound [9]. Medical treatment depends on the size of the abscess and the absence of complications [10]. These complications are: the rupture of the abscess in a hollow organ or in the peritoneal cavity, the extension of close by [11]. The prognosis depends on early diagnosis and appropriate management [12]. Lack of study in the service on this pathology motivated us to do this work.

\section{Method and Material}

This is a 24-month prospective study (January 2016-December 2017) performed in the General Surgery Department at the Kati Reference Health Center (Mali). Have been included all patients admitted for liver abscess and taken care of in the service. During this period 30 patients were hospitalized and treated for liver abscess. Patients on admission received a complete clinical examination, additional examinations. The analysis of these data was done using the SPSS software and the CHI2 test was used with a significance level $\mathrm{P}<0.05$.

\section{Result}

we recorded 30 cases of liver abscess, a hospital frequency of $0.081 \%$. There were 21 men and 9 women, the sex ratio was 2.3 (Figure 1), the average age was 35 years. The most found favoring factors were a history of intestinal amoebiasis $43.3 \%$, chronic alcoholism in $16.7 \%$, toxic products in $3.3 \%$. The most common clinical signs were fever 17 (56.3\%), hepatitis 22 (73.3\%), hepatomegaly 16 (53.3\%) and anorexia $3(10 \%)$, vomiting $2(6.7 \%)$, cough with chest pain 3 (10\%).

The physical signs are summarized in Table 1 . On abdominal ultrasound the abscess collection was localized in the right lobe in $70 \%$, unique in $62 \%$. The blood count performed made it possible to recover leukocytosis in 23 patients (76.7\%) and hyper lymphocytosis in 2 patients, i.e. $6.6 \%$. The average abscess size was $47.1 \mathrm{~mm}$. Amoebic serology performed in all our patients was positive in $80 \%$ of cases, i.e. 24 patients. All patients were seronegative for HIV testing. The cytobacteriological study of pus in 13 patients identified Escherichia coli in 6 cases. The chest X-ray performed in 14 patients allowed to observe the 


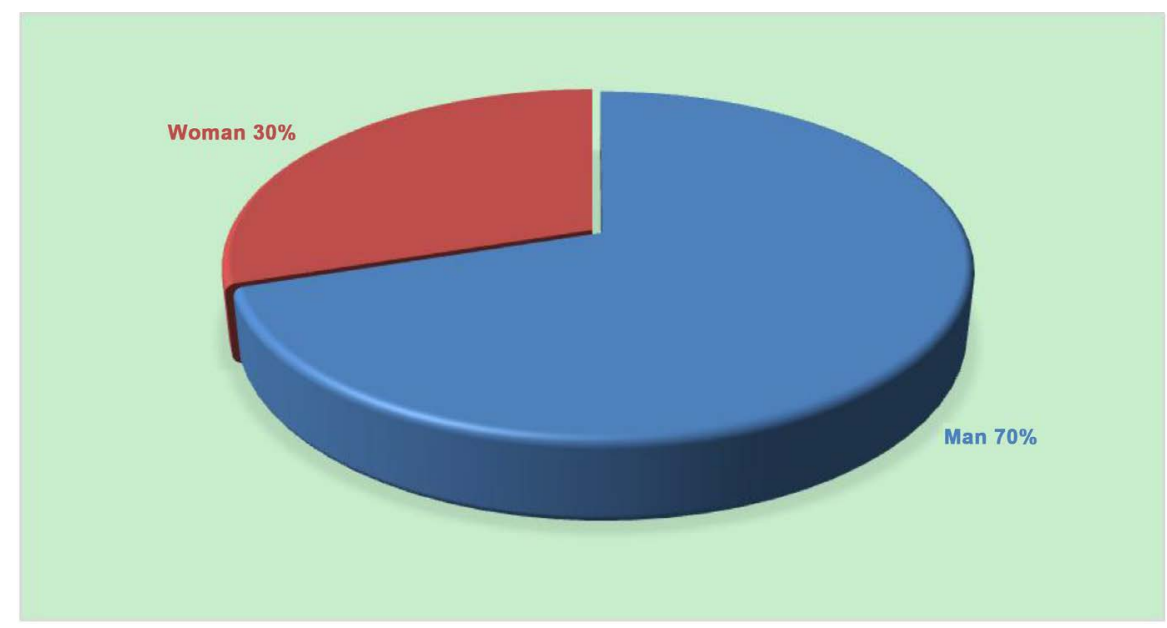

Figure 1. Sex.

Table 1. Physical signs.

\begin{tabular}{ccc}
\hline Physical signs & Frequency & Percentage \\
\hline Hepatomegaly painful & 16 & 53.3 \\
Abdominal defense & 2 & 6.7 \\
Pain in the shaking & 8 & 26.7 \\
Abdominal contracture & 4 & 13.3 \\
Total & 30 & 100 \\
\hline
\end{tabular}

elevation of the right diaphragmatic dome in 4 cases. The true complications were the abscesses of abscesses in the peritoneal cavity requiring surgical treatment in 3 patients (10\%). Echo-guided puncture in 10 patients $(33.3 \%)$ and medical treatment alone was effective in $56.7 \%$ of cases. The average duration of treatment was 5 days and the patients were followed for 6 months, the evolution was favorable. We did not register any deaths.

\section{Discussion}

The abscess of the liver is very often the consequence of the amebiasis that plagues the underprivileged population and it remains relevant in surgical practice in Mali.

Our frequency of $0.081 \%$ does not differ from that of Diaby G.S [8] and that found in intertropical Africa (1\% to 2\%). It is rare in industrialized countries [13]. The abscess of the liver is seen at any age. The mean age of 35.4 years of our study does not differ from that of the literature [14] [15] [16]. The most affected were men with a sex ratio of 2.3. This male predominance has been found by other authors [14] [16]. Clinically the liver abscess is in the form of painful and febrile hepatomegaly (Fontan triad). This functional and physical triad has been found by other authors [8] [17] [18].

Table 2 contains all the functional signs. 
Table 2. Functional signs and authors.

\begin{tabular}{|c|c|c|c|c|}
\hline Authors & $\begin{array}{c}\text { LODHI [17] } \\
\text { Pakistan 2004 }\end{array}$ & $\begin{array}{l}\text { DIABY [8] } \\
\text { Mali } 2011\end{array}$ & $\begin{array}{l}\text { SEETO [18] } \\
\text { U.S.A. } 1999\end{array}$ & $\begin{array}{c}\text { OUR STUDY } \\
\text { Mali } 2017\end{array}$ \\
\hline Effective & 471 & 50 & 56 & 30 \\
\hline Hépatalgie & $\begin{array}{l}410(87 \%) \\
P=0.065\end{array}$ & $\begin{array}{l}34(68 \%) \\
P=0.614\end{array}$ & $\begin{array}{l}47(84 \%) \\
P=0.239\end{array}$ & $22(73.3 \%)$ \\
\hline Fever & $\begin{array}{l}316(67 \%) \\
P=0.240\end{array}$ & $\begin{array}{l}42(84 \%) \\
P=0.007\end{array}$ & $\begin{array}{l}45(80 \%) \\
P=0.019\end{array}$ & $17(56.7 \%)$ \\
\hline vomiting & - & $\begin{array}{l}31(62 \%) \\
P=0.001\end{array}$ & $\begin{array}{c}27(48 \%) \\
P=0.0011\end{array}$ & $2(6.7 \%)$ \\
\hline Anorexia & - & $\begin{array}{l}10(20 \%) \\
P=0.389\end{array}$ & $\begin{array}{c}36(64 \%) \\
P=0.0001\end{array}$ & $3(10 \%)$ \\
\hline emaciation & - & $\begin{array}{c}3(6 \%) \\
P=1\end{array}$ & $\begin{array}{l}16(29 \%) \\
P=0.005\end{array}$ & $1(3.3 \%)$ \\
\hline Cough & $\begin{array}{l}66(14 \%) \\
P=0.164\end{array}$ & $\begin{array}{c}7(14 \%) \\
P=0.248\end{array}$ & $\begin{array}{l}23(41 \%) \\
P=0.002\end{array}$ & $1(3.3 \%)$ \\
\hline
\end{tabular}

The assessment of hepatomegaly depends on the volume of the abscess and the experience of the examiner. The frequency of $26.7 \%$ hepatomegaly in our study differs from that found by the American author [17] [18].

Abdominal ultrasound by its ease of realization, its effectiveness and its moderate cost is the examination of choice in the diagnosis and the follow-up of the disease [10] [19] [20]. It was performed in all our patients upon admission or during hospitalization with $100 \%$ sensitivity, specifying the topography, the number and the size of the hepatic collections.

In our study the right lobe was the seat of the abscess in $70 \%$ of cases. This localization has been observed by all the authors of the literature [8] [17] [21]. This is due to the fact that it constitutes a larger tissue mass than that of the left lobe, as well as the relative importance of its vascularization and imperfect mixing in the portal vein of mesenteric and splenic vein flows [22] [23]. The abscess was unique in $62 \%$, this result does not differ from those of the literature [8] [18] [21]. The detection of serum antibodies confirms the amoebic origin of the liver abscess [22] [24]. This examination performed in all our patients was negative in 6 cases.

The cytobacteriological examination of pus makes it possible to distinguish an amoebic abscess from a bacterial abscess [20] [22].

Escherichia coli was detected in $20 \%$ of the 13 patients who performed this test. Other studies have shown that the detection of amoeba on examination of pus is inconsistent [22] [24]. Retroviral serology was negative in all our patients. Other authors have found an emergence of liver abscess with the AIDS pandemic [14] [25] [26]. Imaging techniques have significantly modified the diagnostic and therapeutic aspects of liver abscesses [22] [24]. These therapeutic techniques differ according to the literature, we have as a method: medical treatment (antiamibien, antibacterial), echo-guided evacuation puncture, percutaneous drainage and conventional surgery [20] [27] [28]. 
Table 3. Evolution and authors.

\begin{tabular}{cccc}
\hline Authors & Effective & Favorable evolution & Death rate \\
\hline DONIKIAN [12] & 22 & $100 \%$ & - \\
& & $\mathrm{P}=0.99$ & - \\
DJOSSOU [13] & 20 & $100 \%$ & \\
& & $\mathrm{P}=0.99$ & $0.5 \%$ \\
Mc GARR [15] 2003 & 178 & $99.5 \%$ & - \\
OUR STUDY Mali 2017 & $\mathbf{3 0}$ & $\mathbf{P}=0.99$ & $\mathbf{1 0 0 \%}$ \\
\hline
\end{tabular}

The medical treatment with nitro-5-imidazoles and/or aminoglycosides associated with third-generation cephalosporins, combined with an echo-guided evacuation puncture is a reference according to the authors [19] [20] [28].

Medical treatment was more common in our study, $56.7 \%$. This result does not differ from those of Djossou in France [14] and Donikian in New Caledonia [12].

Echo-guided evacuation puncture is a very popular therapeutic method today [10] [19]. Our frequency of $33.3 \%$ echo-guided puncture does not differ from that of Donikian [12].

The indication of this echo-guided puncture differs according to the authors. For some, the size of the abscess $>10 \mathrm{~cm}$ and the location at the left lobe are indications [26] [28]. For others, the indication of the puncture was rather based on clinical criteria including the persistence or aggravation of fever and/or hepatitis 48 to 72 hours after the institution of medical treatment [14] [28].

This was also the case in our study.

Surgical treatment of liver abscess is considerably reduced nowadays [20] [22]. These surgical means are reserved for the only complications namely the rupture of the abscess in the peritoneal cavity, pleural, pericardial, the fistulization of the abscess to the skin, in a hollow viscera and finally the failure of the medical treatment.

In our study this treatment was performed in 3 patients (10\%) following rupture of the abscess in the peritoneal cavity.

The evolution of treatment according to the authors is summarized in Table 3.

Hospital stay was 5 days on average.

\section{Conclusion}

The abscess of the liver is a topical pathology in surgical practice in our country. Medical treatment is curative apart from complications. Echo-guided puncture is a very common therapeutic method nowadays that makes it possible to reduce the length of hospital stay. This surgical treatment is reserved for complications.

\section{Conflicts of Interest}

The authors declare no conflicts of interest regarding the publication of this paper. 


\section{References}

[1] Yahchouchi, E. and Cherqu, D. (1998) Abcès non parasitaire du foie. Vol. 15, Elsevier, Paris, 7-15.

[2] Ravdin, J.I. (1995) Amibiase. Clinical Infectious Diseases, 20, 1453-1466. https://doi.org/10.1093/clinids/20.6.1453

[3] Traore, M. (2006) Les abcès du foie en milieu hospitalier de Bamako. Thèse de Médecine, Faculté de Médecine de Bamako, Mali, 586.

[4] Rouviere, H. (1978) Anatomie Humaine. Masson, Paris, 452-458.

[5] Tortora, G.J. and Grabowski, S.R. (2007) Principe d'anatomie et de physiologie. 2nd Edition, De Boeck, 840-846.

[6] Bonkoungou, P., Nacro, B., Sawadogo, A., Bamouni, A. and Sawadogo, A.A. (2000) Liver Abscesses in Children in a Tropicalhospital: A Seven Study in the Bobo Dioulasso Hospital (Burkina Faso). Médecine et Maladies Infectieuses, 30, 773-775. https://doi.org/10.1016/S0399-077X(01)80034-2

[7] Casting, D. and Smail, A. (1999) Anatomie du foie et des voies biliaires. Vol. 12, Elsevier, Paris, 1-10.

[8] Diaby, G.S. (2012) Etude des abcès du foie dans le service de chirurgie générale et pédiatrique du CHU Gabriel Touré. Vol. 329, Thèse de Médecine, Faculté de Médecine de Bamako, Mali.

[9] Ourselin, S. (1978) Anatomie du foi. Masson, Paris, 452-458.

[10] Guittet, V., Ménager, C., Missotte, I., Duparc, B., Verhaegen, F. and Duhamel, J.F. (2004) Les abcès du foie chez l'enfant: Etude rétrospective de 33 cas observés en Nouvelle-Calédonie de 1985 à 2003. Archives de Pédiatrie, 11, 1046-1053.

[11] Gentilini, M., Caume, E. and Danis, M. (1996) Amebiasis in Médicine Intertropical. Flammarion, Paris, 165-172.

[12] Donikian, J.C. (2004) Twenty-Two Cases of Hepatic Abscesses in Children in New Caledonia. Archives de Pédiatrie, 11, 867.

[13] Djossou, F., Malvy, D. and Tamboura, M. (2003) Abces amibien du foie. Analyse de 20 observations et proposition d'un algorithme therapeutique [Amoebic Liver Abscess. Study of 20 Cases with Literature Review]. La revue de médecine interne, 24, 97-106.

[14] Joerg, B., Duy, H. and Hung, D.M. (2003) Treatment of Amoebic Liver Abscess with Metronidazole Alone or in Combination with Ultrasound-Guided Needle Aspiration: A Comparative, Prospective and Randomized Study. Tropical Medicine \& International Health, 8, 1030-1034.

[15] Mc Garr, P.L., Madiba, T.E. and Thomson, S.R. (2003) Amoebic Liver Abscess: Result of a Conservative Management Policy. South African Medical Journal, 93, 132-136.

[16] Albenmousa, A., Sanai, F.M., Singhal, A., et al. (2011) Liver Abscess Presentation and Management in Saudi Arabia and the United Kingdom. Annals of Saudi Medicine, 31, 528-532.

[17] Lodhi, S. (2004) Features Distinguing Amoebic from Pyogenic Liver Abscess. A Review of 577 Adult Cases. Tropical Medicine \& International Health, 9, 718-723. https://doi.org/10.1111/j.1365-3156.2004.01246.x

[18] Seeto, R.K. and Rokey, D.C. (1999) Amoebic Liver Abscess: Epidemiology, Clinical Features and Outcome. Western Journal of Medicine, 170, 104-109.

[19] Silvain, C., Chagneau, C., Derrode, Crugeon, C., Tasu. Service d'hépato-gastro- 
entérologie et d'assistance nutritive. Hôp Jean Bernard. 86021(2).

[20] Molinier, C. and Mennecier, D. (1997) Amibiase hépatique. Encyclopédie MédicoChirurgicale, 10, 7-27.

[21] Weinke, T. (2002) Amoebic Liver Abscess-Rare Need for Percutaneous Treatment Modalities. European Journal of Medical Research, 7, 25-29.

[22] Soubeyrand, J., Leonett, P. and Moncany, G. (1986) Pathologie Africaine: Médicine Interne et Échographie. Masson, Paris, 7-28.

[23] OMS Groupe de travail scientifique (1980) Diarrhees Parasitaires. Bulletin of the World Health Organization, 58, 819-830.

[24] Nussaume, O. and Cherbonnel, G. (1978) L'amibiase hépatique. Encyclopédie Médico-Chirurgicale, 7029, 9.

[25] Liu, C.G. (2001) Amoebic Liver Abscess and Human Immunodeficiency Virus Infection: A Report of Three Cases. Journal of Clinical Gastroenterology, 33, 64.

[26] Lee, K., Kim, E. and Lee, S. (2000) Amoebic Liver Abscess in HIV-Infected Patients. AIDS, 14, 1872-1873. https://doi.org/10.1097/00002030-200008180-00033

[27] Oudou Noya Elie Claude, N.N., Vincent, N. and Charlotte, N.S. (1999) Abcès amibien du foie. Yaoundé Cah Santé, 9, 119-122.

[28] Acuna, S.R., Maguire, J.H. and Wirth, D.F. (2000) Gender Distribution in Asymptomatic and Invasive Amoebiasis. American Journal of Gastroenterology, 95, 1277-1281. 